\title{
Article \\ Mid-Infrared Multispectral Gaseous Stimulated Raman Scattering Laser
}

\author{
Chencheng Shen ${ }^{1,2}$, Xianglong Cai ${ }^{1,3}$, Tiancheng Zheng ${ }^{1,2}$, Yuxi Jia ${ }^{1,2}$, Dong Liu ${ }^{1}$, Jinbo Liu ${ }^{1, *}$ and \\ Jingwei Guo ${ }^{1, *}$
}

Citation: Shen, C.; Cai, X.; Zheng, T.; Jia, Y.; Liu, D.; Liu, J.; Guo, J. MidInfrared Multispectral Gaseous Stimulated Raman Scattering Laser. Appl. Sci. 2021, 11, 11875. https:// doi.org/10.3390/app112411875

Academic Editor: Wolfgang Elsaesser

Received: 16 November 2021

Accepted: 12 December 2021

Published: 14 December 2021

Publisher's Note: MDPI stays neutral with regard to jurisdictional claims in published maps and institutional affiliations.

Copyright: (c) 2021 by the authors. Licensee MDPI, Basel, Switzerland. This article is an open access article distributed under the terms and conditions of the Creative Commons Attribution (CC BY) license (https:// creativecommons.org/licenses/by/ $4.0 /)$.
1 Key Laboratory of Chemical Lasers, Dalian Institute of Chemical Physics, Chinese Academy of Sciences, Dalian 116023, China; shener@dicp.ac.cn (C.S.); caixl@dicp.ac.cn (X.C.); ztc@dicp.ac.cn (T.Z.); yxjia@dicp.ac.cn (Y.J.); dongl@dicp.ac.cn (D.L.)

2 University of Chinese Academy of Sciences, Beijing 100049, China

3 School of Science, Changchun University of Science and Technology, Changchun 130022, China

* Correspondence: liujinbo@dicp.ac.cn (J.L.); jingweiguo@dicp.ac.cn (J.G.)

Featured Application: Advances in Middle Infrared (Mid-IR) Lasers and Their Application.

Abstract: We demonstrated mid-infrared gaseous stimulated Raman scattering lasers in free space. Mixed gases of hydrogen and deuterium were used as Raman gain media in one Raman cell. Pumped by laser pulses at $1064 \mathrm{~nm}$, the first Stokes Raman components at $1560 \mathrm{~nm}$ and $1907 \mathrm{~nm}$ were generated. A four-wave mixing process with the pump laser at $1064 \mathrm{~nm}$ and Raman lasers at $1560 \mathrm{~nm}$ and $1907 \mathrm{~nm}$ contributed to dramatically reducing the threshold of mid-IR laser generation at $4432 \mathrm{~nm}$. The maximum output peak power of a mid-IR laser at $4432 \mathrm{~nm}$ reached $121 \mathrm{~kW}$. Furthermore, by scattering on the rotational transition of deuterium, multispectral mid-IR Raman lasers at wavelengths of $2071 \mathrm{~nm}, 2266 \mathrm{~nm}, 2604 \mathrm{~nm}, 2920 \mathrm{~nm}, 3322 \mathrm{~nm}, 3743 \mathrm{~nm}, 4432 \mathrm{~nm}$, and $5431 \mathrm{~nm}$ were also generated. Our results show that this is a convenient method to reduce the threshold and achieve a high power output with mid-IR Raman lasers.

Keywords: mid-infrared laser; stimulated Raman scattering; four-wave mixing; multispectral Raman lasers

\section{Introduction}

Mid-infrared (mid-IR) laser sources in the range of 2-6 $\mu \mathrm{m}$ have important applications for atmospheric sounding, the detection of organic gaseous pollutants, biomedical surgery, defense technology, gas detection, and higher harmonics generation technology [1-8]. The stimulated Raman scattering (SRS) process is an effective method of broadening the laser spectral range and generating new wavelength lasers [9-11]. It is very convenient to realize the down-conversion of laser frequencies and achieve a mid-IR Raman laser output by the SRS process. By using solid-state materials as Raman gain media, mid-IR lasers have been widely studied and reported [12,13]. Large gain coefficients and the high thermal conductivity of solid crystals can be beneficial to realizing a high conversion efficiency with mid-IR Raman lasers. However, the development of high-energy Raman laser output is limited by the absorption of crystals in the mid-IR range and the low optical damage threshold. Moreover, the Raman shifts of solid crystals are about $1000 \mathrm{~cm}^{-1}$, which is not large enough to generate wide-ranging mid-IR Raman lasers. Gas Raman gain media in hollow-core fiber (HCF) have also been demonstrated to generate mid-IR Raman lasers, but the strong loss of silica over wavelengths of $5 \mu \mathrm{m}$ limits the generation of silica antiresonant hollow-core fiber Raman lasers [14-18]. With a much higher damage threshold, gaseous Raman media in free space can withstand large pump energy. However, it is very hard to generate mid-IR Raman lasers due to the low Raman gain of gaseous media.

In this work, we reported the generation of mid-IR multispectral gaseous Raman lasers in free space by using a mixed gas of hydrogen $\left(\mathrm{H}_{2}\right)$ and deuterium $\left(\mathrm{D}_{2}\right)$ as the Raman gain 
medium. The four-wave mixing (FWM) process contributed to dramatically reducing the threshold of mid-IR Raman laser generation. A $4432 \mathrm{~nm}$ Raman laser with a peak power of $121 \mathrm{~kW}$ was obtained, and multispectral mid-IR Raman lasers at wavelengths of $2071 \mathrm{~nm}$, $2266 \mathrm{~nm}, 2604 \mathrm{~nm}, 2920 \mathrm{~nm}, 3322 \mathrm{~nm}, 3743 \mathrm{~nm}, 4432 \mathrm{~nm}$, and $5431 \mathrm{~nm}$ were also generated.

\section{Experimental Setup}

The experimental setup is shown in Figure 1. A Q-switched solid-state Nd:YAG laser (Nimma-900, Beamtech Optronics Co., Ltd., Beijing, China) at $1064 \mathrm{~nm}$ was used as the pump source. The laser beam divergence angle was approximately $0.5 \mathrm{mrad}$, and the beam diameter was approximately $9 \mathrm{~mm}$. The pulse width was $9 \mathrm{~ns}$, and the repetition rate used in this experiment was $1 \mathrm{~Hz}$. The output beam passed through a half-wave plate (HWP) and a polarizing beam splitter prism (PBSP). The pump power could be adjusted continuously by rotating the HWP. Then, the linearly polarized pump laser passed through a quarter-wave plate (QWP) and turned to the circular polarization. The pump laser was focused into a Raman cell through a convex lens L1 with focal length of $2 \mathrm{~m}$. The Raman cell, created from a $4 \mathrm{~m}$ stainless steel tube and two calcium fluoride $\left(\mathrm{CaF}_{2}\right)$ windows, was filled with a mixed gas of $0.4 \mathrm{MPa} \mathrm{H}_{2}$ and $2.0 \mathrm{MPa} \mathrm{D}_{2}$ of $99.995 \%$ purity.

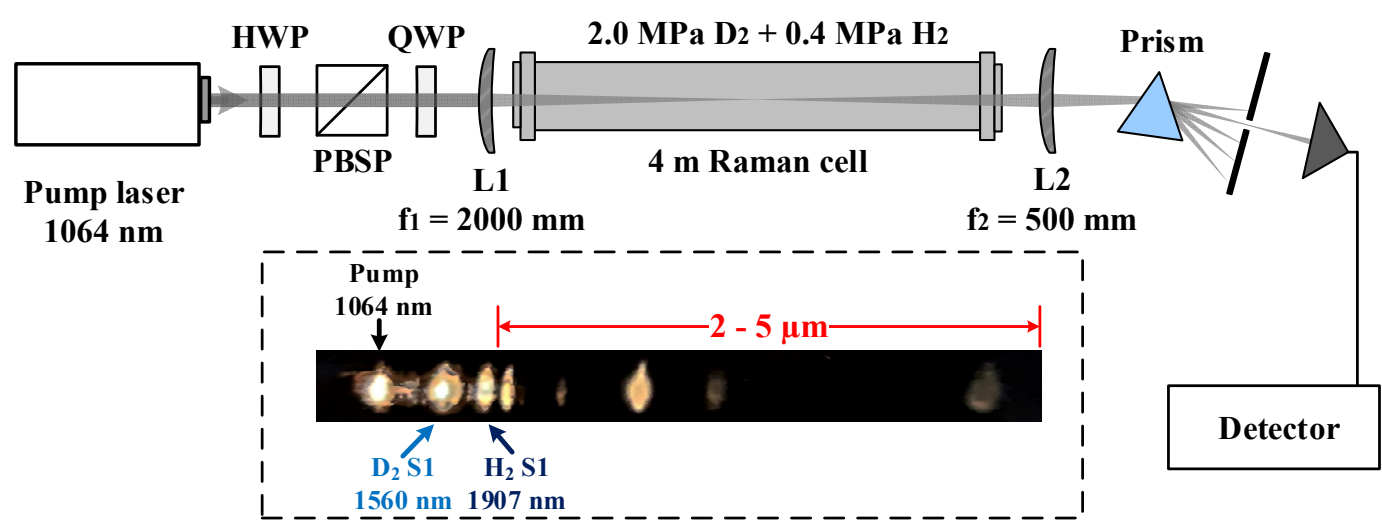

Figure 1. Schematic of the experimental setup. The inset shows the burn marks of Raman components with different wavelengths.

The SRS and FWM processes occurred in the Raman cell, and a series of mid-IR Raman lasers were generated and separated by a $\mathrm{CaF}_{2}$ lens $\mathrm{L} 2$, a CaF 2 prism and a slit. Photographic paper was used to locate the burn marks of Raman components with different wavelengths, as shown in the inset of Figure 1. The spectra and waveform of the output Raman lasers were detected by a monochromator (Micro HR MHRA-2A-MS, HORIBA, Beijing, China) and a photoelectric probe (PVI-2TE-4, VIGO System, Ozarow Mazowiecki, Poland), and the laser pulse energy was detected by an energy meter (QE25LP-S-MB-D0, GENTEC-EO, Beijing, China).

\section{Results and Discussion}

\subsection{High-Power Mid-IR Laser at $4432 \mathrm{~nm}$}

In the Raman cell, with a $1064 \mathrm{~nm}$ laser pump, the SRS processes occurred in the mixture of $\mathrm{H}_{2}$ and $\mathrm{D}_{2}$ gases. When the pump laser was scattered on the vibrational transitions of $\mathrm{H}_{2}$ with a Raman shift of $\Omega_{R}^{v i b}\left(\mathrm{H}_{2}\right)=4155 \mathrm{~cm}^{-1}$, the first Stokes (S1) at $1907 \mathrm{~nm}$ was generated. Similarly, when the pump laser was scattered on the vibrational transitions of $\mathrm{D}_{2}$ with a Raman shift of $\Omega_{R}^{v i b}\left(\mathrm{D}_{2}\right)=2987 \mathrm{~cm}^{-1}$, the first Stokes (S1) at $1560 \mathrm{~nm}$ and the second Stokes (S2) at $2920 \mathrm{~nm}$ was generated.

With the generation of $1560 \mathrm{~nm}$ and $1907 \mathrm{~nm}$ Raman lasers, FWM processes could occur in the Raman cell. A mid-IR Raman laser at $4432 \mathrm{~nm}$ would be obtained by the FWM process of the pump laser at $1064 \mathrm{~nm}$, and Raman lasers at $1560 \mathrm{~nm}$ and $1907 \mathrm{~nm}$. The scheme of the FWM process is shown in Figure 2. 


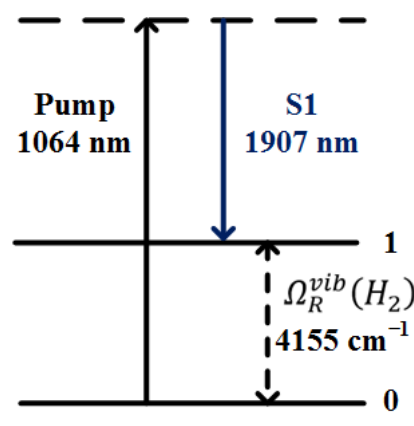

$\mathbf{H}_{2}$

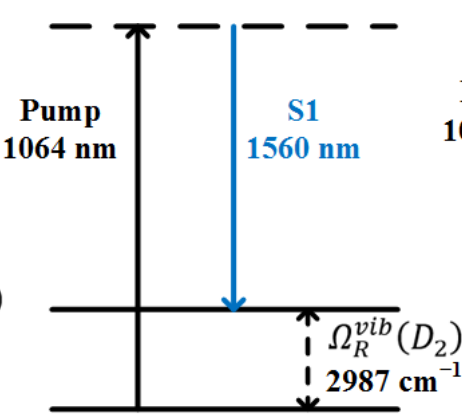

$\mathbf{D}_{2}$

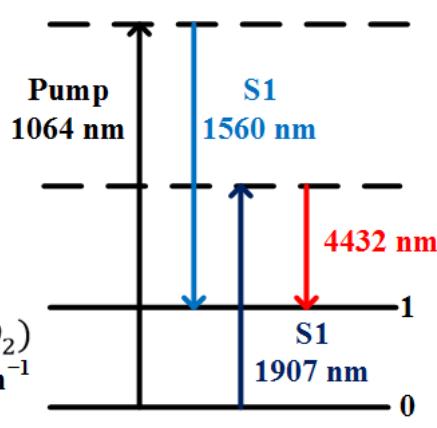

FWM

Figure 2. Schematic representation of the mid-IR $4432 \mathrm{~nm}$ Raman laser generation by FWM.

According to Bjorklund's research, the generated power of a $4432 \mathrm{~nm}$ laser by the FWM process above can be given by $[19,20]$ :

$$
P_{4}=B p^{2} P_{1} P_{2} P_{3} \cdot \exp (b|\Delta k|)
$$

where $B$ is a constant; $p$ is the gas pressure in the Raman cell; $b$ is the laser confocal parameter; $P_{1}, P_{2}, P_{3}$ are the powers of the pump laser at $1064 \mathrm{~nm}$, and the Raman lasers at $1560 \mathrm{~nm}$ and $1907 \mathrm{~nm}$, separately; and $\Delta k$ is the wave-vector mismatch caused by the dispersion of the Raman medium. In this case, the wave-vector mismatch $\Delta k$ can be defined as:

$$
\Delta k=k_{1}+k_{2}-k_{3}
$$

where $k_{1}$ and $k_{2}$ are the wave vectors of the Raman lasers at $1560 \mathrm{~nm}$ and $1907 \mathrm{~nm}$, separately, and $k_{3}$ is the wave vector of the pump laser at $1064 \mathrm{~nm}$.

According to the Equation (1), the output power of a mid-IR laser at $4432 \mathrm{~nm}$ is proportional to a product of the output powers of the pump laser at $1064 \mathrm{~nm}$, and Raman lasers at $1560 \mathrm{~nm}$ and $1907 \mathrm{~nm}$, so the generation of a mid-IR laser at $4432 \mathrm{~nm}$ by the FWM process has no threshold. After generating a $4432 \mathrm{~nm}$ laser seed, it could be further amplified by the SRS process in the Raman cell. In comparison with the cascade SRS process, this work provided a much easier method to achieve a mid-IR laser output.

In the Raman cell, due to the high Raman gain coefficient of the vibrational transitions, high-energy Raman lasers at $1560 \mathrm{~nm}, 1907 \mathrm{~nm}$, and $2920 \mathrm{~nm}$ could be obtained by the SRS process in the mixture of $\mathrm{H}_{2}$ and $\mathrm{D}_{2}$ gases. The output powers of different Raman components were investigated and are shown in Figure 3. Had the SRS process occurred in a different gas pressure of Raman media, the conversion efficiencies of Raman components would be influenced greatly [21,22]. To obtain high-energy mid-IR Raman laser output, the FWM process should be matched well by adjusting the partial pressure of $\mathrm{H}_{2}$ and $\mathrm{D}_{2}$ in the Raman cell. As shown in Figure 3a, while the $1064 \mathrm{~nm}$ laser pumped the mixed gas of $0.4 \mathrm{MPa} \mathrm{H}_{2}$ and $2.0 \mathrm{MPa} \mathrm{D}_{2}$, the output energies of the $\mathrm{S} 1$ Raman lasers at $1560 \mathrm{~nm}$ and $1907 \mathrm{~nm}$ were approximately equal at their highest conversion efficiencies. Similar output energies would contribute to generating a mid-IR laser at $4432 \mathrm{~nm}$ by the FWM process and the SRS amplification process. By slightly increasing the partial pressure of $\mathrm{H}_{2}$ to $0.5 \mathrm{MPa}$, the output energy of the $\mathrm{S} 1$ Raman laser at $1907 \mathrm{~nm}$ could reach a higher level than the S1 Raman laser at $1560 \mathrm{~nm}$ of $\mathrm{D}_{2}$, as shown in Figure $3 \mathrm{~b}$, which resulted in the suppression of Raman conversion at $1560 \mathrm{~nm}$ and $2920 \mathrm{~nm}$ of $\mathrm{D}_{2}$. This condition was unfavorable for the generation of mid-IR Raman lasers. In the same experimental conditions, the output energy of the mid-IR laser at $4432 \mathrm{~nm}$ generated by the mixed gas of $0.5 \mathrm{MPa} \mathrm{H}_{2}$ and 2.0 MPa $\mathrm{D}_{2}$ was too weak to be recorded by an energy meter. 

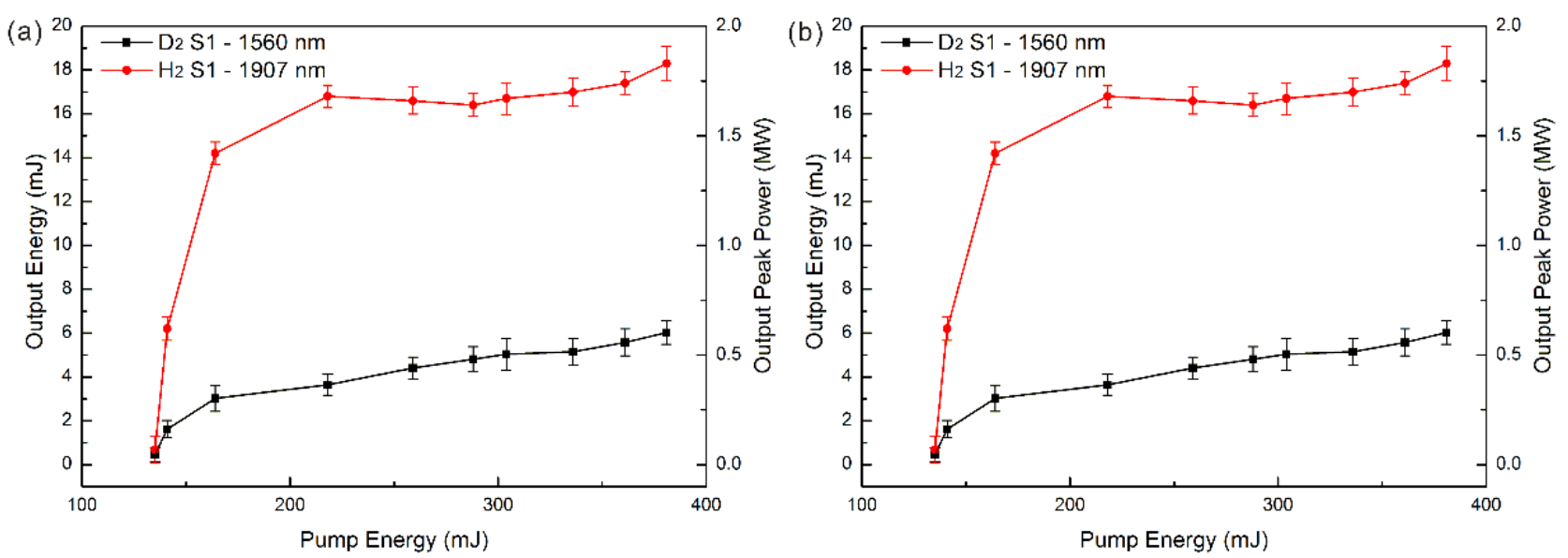

Figure 3. Output power of Raman components of (a) mixed gas of $0.4 \mathrm{MPa} \mathrm{H}_{2}$ and $2.0 \mathrm{MPa} \mathrm{D}_{2}$; (b) mixed gas of $0.5 \mathrm{MPa}$ $\mathrm{H}_{2}$ and $2.0 \mathrm{MPa} \mathrm{D}$.

Furthermore, according to Equations (1) and (2), it could be found that the wavevector mismatch $\Delta k$ should be satisfied to generate a mid-IR laser by the FWM process. Ishaaya's research concluded that phase-matching conditions would be influenced by focus conditions [23]. While a lens of a short focal length is used to focus the pump laser into Raman cells, at the focus, the numerical aperture is relatively large, so the maximum angle between the pump laser and Raman lasers may be large enough to satisfy the wave-vector match [24]. In this case, a mid-IR laser is easily generated by the FWM process. However, the power density would be so high that the laser pulses could ionize Raman media at the focus, and the laser-induced breakdown would deteriorate the conversion of Raman lasers [25]. On the other hand, while a lens of long focal length is used to focus the pump laser, at the focus, the numerical aperture is small, and the maximum angle between the pump and Stokes waves may be too small to satisfy the wave-vector match. In this case, the FWM process is limited, and it is hard to generate a mid-IR laser. In our study, by using a lens with a focal length longer than $2 \mathrm{~m}$, the mid-IR laser at $4432 \mathrm{~nm}$ could not be observed.

In summary, compared with cascade SRS, the FWM process could dramatically reduce the threshold of mid-IR Raman laser generation. By further SRS amplification, a mid-IR $4432 \mathrm{~nm}$ laser achieved high peak power output. The SRS process of the vibrational first Stokes Raman laser of $\mathrm{H}_{2}$ pumped by a $1560 \mathrm{~nm}$ laser contributed to the amplification, and the SRS process of the vibrational first Stokes Raman laser of $D_{2}$ pumped by a $1907 \mathrm{~nm}$ laser was also conducive to it. The waveform of the $4432 \mathrm{~nm}$ laser was recorded and is shown in Figure 4a. Due to the pulse compression of the SRS process, the pulse width of the $4432 \mathrm{~nm}$ laser was smaller than the pump laser, which was only $2.8 \mathrm{~ns}$. The output power of the mid-IR laser at $4432 \mathrm{~nm}$ is also shown in Figure $4 \mathrm{~b}$. It can be seen that the maximum output peak power reached $121 \mathrm{~kW}$, pumped by the laser at $1064 \mathrm{~nm}$ with a pulse energy of $431 \mathrm{~mJ}$ and linewidth of $1 \mathrm{~cm}^{-1}$. However, the output energy of the $4432 \mathrm{~nm}$ laser would decay due to the laser-induced breakdown mentioned above when the pump energy was beyond $440 \mathrm{~mJ}$. 

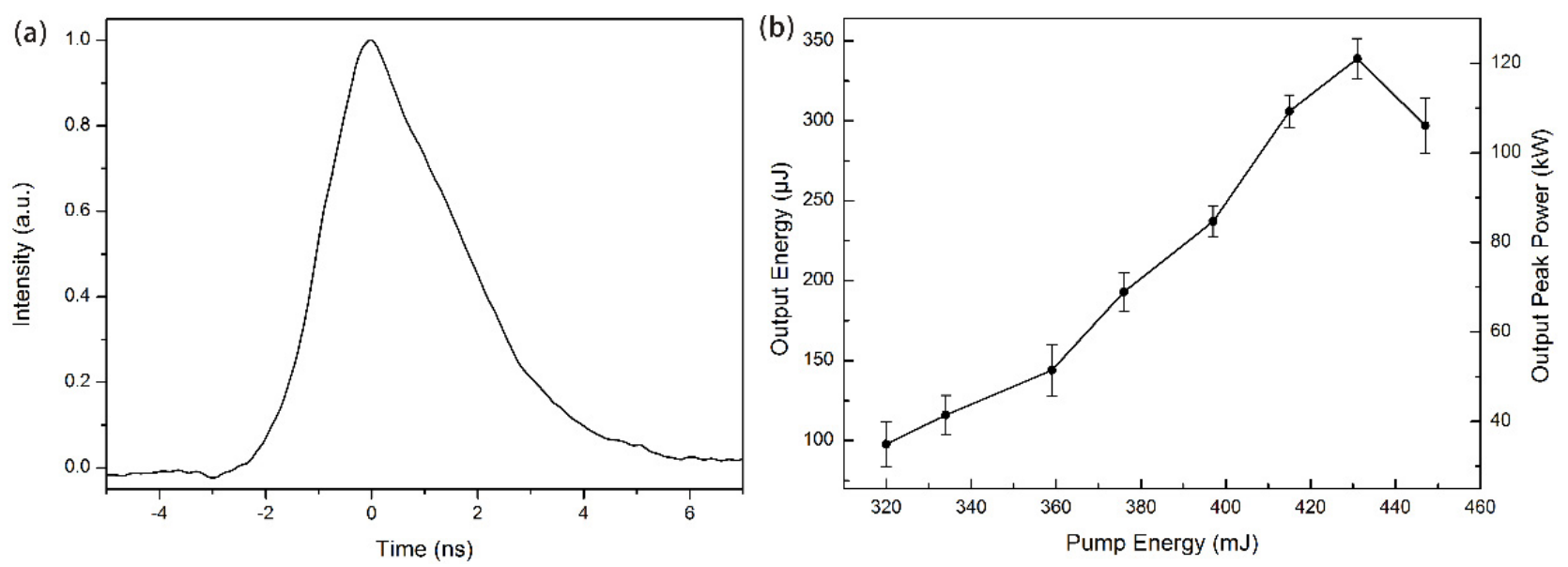

Figure 4. Pulse shape (a) and energy conversion curve (b) of the mid-IR laser at $4432 \mathrm{~nm}$.

\subsection{2-6 $4 m$ Multispectral Mid-IR Raman Laser}

With the generation of high-energy Raman components at wavelengths of $1907 \mathrm{~nm}$, $2920 \mathrm{~nm}$, and $4432 \mathrm{~nm}$, these Raman lasers could be used as pump sources and scattered on the rotational transition of $\mathrm{D}_{2}$ with Raman shift of $\Omega_{R}^{\text {rot }}\left(\mathrm{D}_{2}\right)=415 \mathrm{~cm}^{-1}$. The circular polarization of the pump laser could contribute to reducing the threshold of the rotational Raman scattering of $D_{2}[26,27]$. Thus, pumped by the laser at $1064 \mathrm{~nm}$ with a pulse energy of $431 \mathrm{~mJ}$, multispectral mid-IR Raman lasers in the range of 2-6 $\mu \mathrm{m}$ could be generated as: the first Stokes at $2071 \mathrm{~nm}$ and the second Stokes at $2266 \mathrm{~nm}$, pumped by a $1907 \mathrm{~nm}$ laser; the first Stokes at $3322 \mathrm{~nm}$ and the first anti-Stokes at $2604 \mathrm{~nm}$, pumped by a $2920 \mathrm{~nm}$ laser; the first Stokes at $5431 \mathrm{~nm}$ and the first anti-Stokes at $3743 \mathrm{~nm}$, pumped by a $4432 \mathrm{~nm}$ laser. The spectra of the mid-IR Raman lasers are shown in Figure 5, and the SRS processes generating all the mid-IR Raman components in the range of 2-6 $\mu \mathrm{m}$ are shown in Table 1.

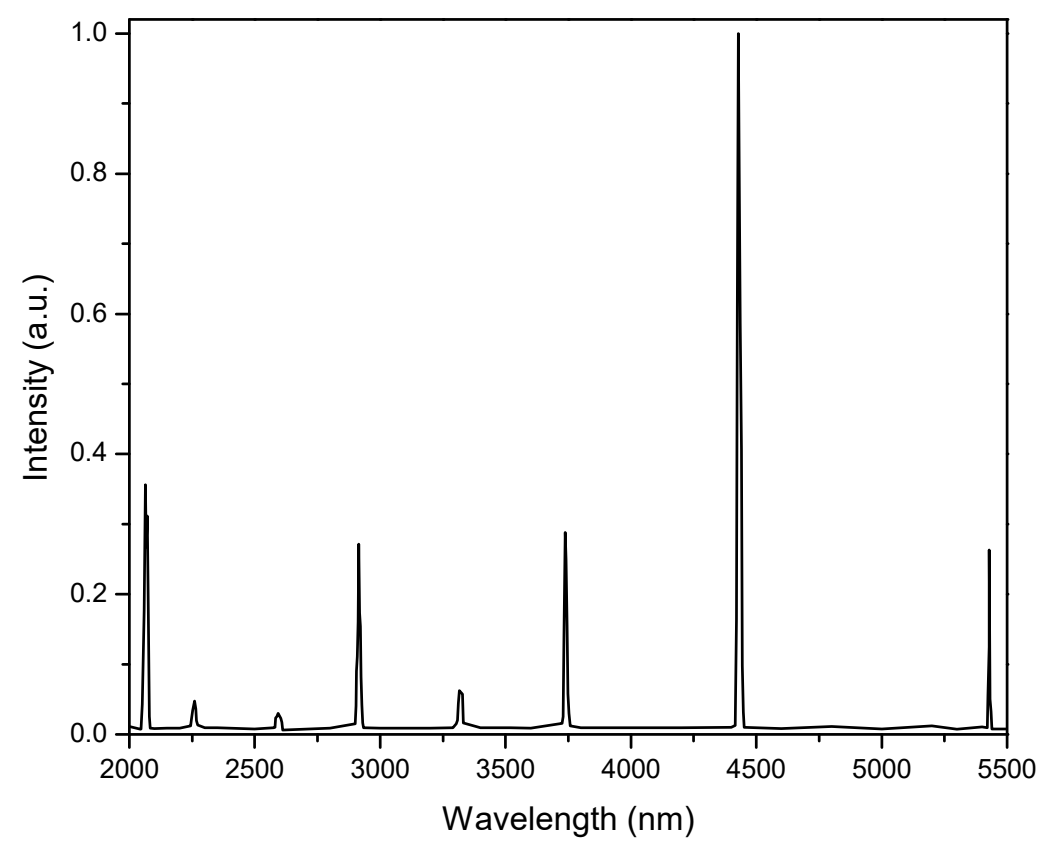

Figure 5. Mid-IR spectra of the Raman lasers generated by the $1064 \mathrm{~nm}$ laser pump for the mixture of $\mathrm{H}_{2}$ and $\mathrm{D}_{2}$ gases. 
Table 1. The mid-IR Raman components generated by each SRS process.

\begin{tabular}{cc}
\hline Wavelength & SRS Process \\
\hline $2071 \mathrm{~nm}$ & $\omega_{1907 \mathrm{~nm}}-\Omega_{R}^{\text {rot }}\left(\mathrm{D}_{2}\right)$ \\
$2266 \mathrm{~nm}$ & $\omega_{1907 \mathrm{~nm}}-2 \Omega_{R}^{\text {rot }}\left(\mathrm{D}_{2}\right)$ \\
$2604 \mathrm{~nm}$ & $\omega_{2920 \mathrm{~nm}}+\Omega_{R}^{\text {rot }}\left(\mathrm{D}_{2}\right)$ \\
$2920 \mathrm{~nm}$ & $\omega_{1064 \mathrm{~nm}}-2 \Omega_{R}^{\text {vib }}\left(\mathrm{D}_{2}\right)$ \\
$3322 \mathrm{~nm}$ & $\omega_{2920 \mathrm{~nm}}-\Omega_{R}^{\text {rot }}\left(\mathrm{D}_{2}\right)$ \\
$3743 \mathrm{~nm}$ & $\omega_{4432 \mathrm{~nm}}+\Omega_{R}^{\text {rot }}\left(\mathrm{D}_{2}\right)$ \\
$4432 \mathrm{~nm}$ & $\omega_{1064 \mathrm{~nm}}-\Omega_{R}^{\text {vib }}\left(\mathrm{D}_{2}\right)-\Omega_{R}^{\text {vib }}\left(\mathrm{H}_{2}\right)$ \\
$5431 \mathrm{~nm}$ & $\omega_{4432 \mathrm{~nm}}-\Omega_{R}^{\text {rot }}\left(\mathrm{D}_{2}\right)$ \\
\hline
\end{tabular}

In this work, by using a $\mathrm{CaF}_{2}$ prism, the output mid-IR Raman lasers could be dispersed, and a slit could be used to select a specific wavelength that we would need in these mid-IR Raman lasers. Furthermore, some previous studies showed that it would be possible to finely tune the frequencies of Raman lasers by using wavelength-tunable laser sources, or with a tunable seed injection $[28,29]$.

In our experiment, it is possible to generate the second Stokes laser at $9.2 \mu \mathrm{m}$. However, our experimental condition makes the detection of $9.2 \mu \mathrm{m}$ very difficult. First, the optical conversion efficiency of $9.2 \mu \mathrm{m}$ is expected to lead to limitations. Even if it has a similar photon conversion efficiency to a $\mathrm{D}_{2}$ second Stokes $(2.92 \mu \mathrm{m})$ Raman laser, the $9.2 \mu \mathrm{m}$ Raman laser would have much lower energy due to large quantum deficiency. Furthermore, a $\mathrm{CaF}_{2}$ exit window and prism were used in this experiment. $\mathrm{CaF}_{2}$ has strong absorption at $9.2 \mu \mathrm{m}$, and this will further decrease energy of a $9.2 \mu \mathrm{m}$ laser. Output Raman lasers were dispersed by a prism, focused by a $\mathrm{CaF}_{2}$ lens, with a burn mark used to know the exact position of the Raman line before the energy of the Raman laser was measured. However, in our experiment, even if a $9.2 \mu \mathrm{m}$ Raman laser was generated, it would still be very difficult to obtain the burn mark, and, consequently, the energy of the $9.2 \mu \mathrm{m}$ Raman laser could not be measured. In fact, if the second Stokes laser at $9.2 \mu \mathrm{m}$ is expected to be generated, a pure hydrogen and linear polarization pump laser should be used, and a Herriot multiple pass Raman configuration will also benefit the generation of a $9.2 \mu \mathrm{m}$ Raman laser.

\section{Conclusions}

In conclusion, we have first demonstrated multispectral mid-IR gaseous Raman lasers in free space in the range of 2-6 $\mu \mathrm{m}$ by using a mixture of $\mathrm{H}_{2}$ and $\mathrm{D}_{2}$ as Raman gain medium. A high-power $1064 \mathrm{~nm}$ laser was used to pump the vibrational transitions of $\mathrm{H}_{2}$ and $\mathrm{D}_{2}$ to generate the first Stokes Raman components at wavelengths of $1560 \mathrm{~nm}$ and $1907 \mathrm{~nm}$. The FWM process of $1064 \mathrm{~nm}, 1560 \mathrm{~nm}$, and $1907 \mathrm{~nm}$ lasers was carried out and reduced the threshold of mid-IR Raman laser generation. With further SRS amplification, a $4.4 \mu \mathrm{m}$ Raman laser was obtained and a maximum peak power of $121 \mathrm{~kW}$ was achieved. Furthermore, the smaller Raman shift of the rotational transition of $\mathrm{D}_{2}$ contributed to generating more mid-IR Raman components. Theoretically, by using a multipass Raman cell with a longer gain length and selecting an active gas mixture, mid-IR Raman lasers with more spectra and a wider wavelength range can be obtained, and even far-infrared Raman lasers can be generated by this method.

Author Contributions: Conceptualization, C.S., X.C. and T.Z.; methodology, C.S. and T.Z.; formal analysis, D.L.; investigation, Y.J.; data curation, D.L.; writing-original draft preparation, C.S.; writing-review and editing, J.G. and J.L.; funding acquisition, C.S. and J.L. All authors have read and agreed to the published version of the manuscript.

Funding: This research was funded by National Natural Science Foundation of China (22073101) and the Innovation Foundation of Key Lab of Chemical Laser of Dalian Institute of Chemical Physics (KLCL-20S09).

Institutional Review Board Statement: Not applicable. 
Informed Consent Statement: Not applicable.

Data Availability Statement: Data sharing is not applicable to this article.

Conflicts of Interest: The authors declare no conflict of interest.

\section{References}

1. Vodopyanov, K.L. Laser-Based Mid-Infrared Sources and Applications; John Wiley \& Sons: Hoboken, NJ, USA, 2020.

2. Walsh, B.M.; Lee, H.R.; Barnes, N.P. Mid infrared lasers for remote sensing applications. J. Lumin. 2016, 169, 400-405. [CrossRef]

3. Jackson, S. Towards high-power mid-infrared emission from a fibre laser. Nat. Photonics 2012, 6, 423-431. [CrossRef]

4. Werle, P.; Slemr, F.; Maurer, K.; Kormann, R.; Mücke, R.; Jänker, B. Near- and mid-infrared laser-optical sensors for gas analysis. Opt. Lasers Eng. 2002, 37, 101-114. [CrossRef]

5. Gandolfi, M.; Tognazzi, A.; Rocco, D.; de Angelis, C.; Carletti, L. Near-unity third-harmonic circular dichroism driven by quasi-bic in asymmetric silicon metasurfaces. arXiv 2021, arXiv:2102.08027.

6. Koshelev, K.; Tang, Y.; Li, K.; Choi, D.-Y.; Li, G.; Kivshar, Y. Nonlinear Metasurfaces Governed by Bound States in the Continuum. ACS Photonics 2019, 6, 1639-1644. [CrossRef]

7. Pitruzzello, G.; Krauss, T.F. Photonic crystal resonances for sensing and imaging. J. Opt. 2018, 20, 073004. [CrossRef]

8. Tognazzi, A.; Rocco, D.; Gandolfi, M.; Locatelli, A.; Carletti, L.; De Angelis, C. High Quality Factor Silicon Membrane Metasurface for Intensity-Based Refractive Index Sensing. Optics 2021, 2, 193-199. [CrossRef]

9. Li, D.J.; Yang, G.L.; Chen, F.; Xie, J.J.; Zhang, L.M.; Guo, J.; Shao, C.L.; Peng, Z.Q.; Lu, Q.P. Stimulated rotational Raman scattering at multiwavelength under tea CO2 laser pumping with a multiple-pass cell. Laser Phys. 2012, 22, 937-940. [CrossRef]

10. Supradeepa, V.R.; Nichsolson, J.W.; Headley, C.E.; Yan, M.F.; Palsdottir, B.; Jakobsen, D. A high efficiency architecture for cascaded Raman fiber lasers. Opt. Express 2013, 21, 7148-7155. [CrossRef]

11. Shen, C.; Cai, X.; Sang, Y.; Zheng, T.; Li, Z.; Liu, D.; Liu, W.; Guo, J. Investigation of multispectral SF6 stimulated Raman scattering laser. Chin. Opt. Lett. 2020, 18, 051402. [CrossRef]

12. Sabella, A.; Piper, J.A.; Mildren, R.P. Diamond Raman laser with continuously tunable output from 3.38 to $3.80 \mu \mathrm{m}$. Opt. Lett. 2014, 39, 4037-4040. [CrossRef]

13. Cheng, P.; Zhao, J.; Xu, F.; Zhou, X.; Wang, G. Diode-pumped mid-infrared YVO4 Raman laser at 2418 nm. Appl. Phys. A 2017, 124, 5. [CrossRef]

14. Li, Z.; Huang, W.; Cui, Y.; Wang, Z. Efficient mid-infrared cascade Raman source in methane-filled hollow-core fibers operating at $28 \mu \mathrm{m}$. Opt. Lett. 2018, 43, 4671-4674. [CrossRef] [PubMed]

15. Gladyshev, A.V.; Kosolapov, A.F.; Khudyakov, M.; Yatsenko, Y.P.; Kolyadin, A.; Krylov, A.A.; Pryamikov, A.D.; Biriukov, A.S.; Likhachev, M.E.; Bufetov, I.A.; et al. 4.4- $\mathrm{mm}$ Raman laser based on hollow-core silica fibre. Quantum Electron. 2017, 47, 491-494. [CrossRef]

16. Gladyshev, A.V.; Kosolapov, A.F.; Khudyakov, M.M.; Yatsenko, Y.P.; Kolyadin, A.N.; Krylov, A.A.; Pryamikov, A.D.; Biriukov, A.S.; Likhachev, M.E.; Bufetov, I.A. 2.9, 3.3, and $3.5 \mu \mathrm{m}$ raman lasers based on revolver hollow-core silica fiber filled by $1 \mathrm{H} 2 / \mathrm{D} 2$ gas mixture. IEEE J. Sel. Top. Quantum Electron. 2018, 24, 1-8. [CrossRef]

17. Wang, Y.; Dasa, M.K.; Adamu, A.I.; Antonio-Lopez, J.E.; Habib, S.; Correa, R.A.; Bang, O.; Markos, C. High pulse energy and quantum efficiency mid-infrared gas Raman fiber laser targeting $\mathrm{CO}_{2}$ absorption at $4.2 \mu \mathrm{m}$. Opt. Lett. 2020, 45, $1938-1941$. [CrossRef]

18. Gao, S.-F.; Wang, Y.-Y.; Ding, W.; Jiang, D.-L.; Gu, S.; Zhang, X.; Wang, P. Hollow-core conjoined-tube negative-curvature fibre with ultralow loss. Nat. Commun. 2018, 9, 1-6. [CrossRef]

19. Björklund, G. Effects of focusing on third-order nonlinear processes in isotropic media. IEEE J. Quantum Electron. 1975, 11, 287-296. [CrossRef]

20. Kleinman, D.A.; Ashkin, A.; Boyd, G.D. Second-Harmonic Generation of Light by Focused Laser Beams. Phys. Rev. 1966, 145, 338-379. [CrossRef]

21. Bloembergen, N.; Bret, G.; Lallemand, P.; Pino, A.; Simova, P. Controlled stimulated Raman amplification and oscillation in hydrogen gas. IEEE J. Quantum Electron. 1967, 3, 197-201. [CrossRef]

22. Chu, Z.; Singh, U.N.; Wilkerson, T.D. Multiple stokes wavelength generation in H2, D2, and CH4 for lidar aerosol measurements. Appl. Opt. 1991, 30, 4350-4357. [CrossRef] [PubMed]

23. Ben Yehud, L.; Belker, D.; Ravnitzki, G.; Ishaaya, A.A. Competition between stimulated Raman and Brillouin scattering processes in CF_4 gas. Opt. Lett. 2014, 39, 1026. [CrossRef]

24. Boyd, R. Nonlinear Optics, 2nd ed.; Academic Press: Amsterdam, The Netherlands, 2003.

25. Yagi, T.; Huo, Y. Laser-induced breakdown in $\mathrm{H}_{2}$ gas at $248 \mathrm{~nm}$. Appl. Opt. 1996, 35, 3183-3184. [CrossRef]

26. Minck, R.W.; Hagenlocker, E.E.; Rado, W.G. Stimulated Pure Rotational Raman Scattering in Deuterium. Phys. Rev. Lett. 1966, 17, 229-231. [CrossRef]

27. Perrone, M.R.; Piccinno, V.; De Nunzio, G.; Nassisi, V. Dependence of rotational and vibrational Raman scattering on focusing geometry. IEEE J. Quantum Electron. 1997, 33, 938-944. [CrossRef] 
28. Huang, W.; Li, Z.; Cui, Y.; Zhou, Z.; Wang, Z. Efficient, watt-level, tunable $1.7 \mu \mathrm{m}$ fiber Raman laser in H2-filled hollow-core fibers. Opt. Lett. 2020, 45, 475-478. [CrossRef]

29. Shen, C.; Cai, X.; Su, X.; Zheng, T.; Liu, J.; Chen, Y.; Jia, Y.; Liu, D.; Guo, J. Wavelength-tunable narrow-linewidth gaseous Raman laser. Appl. Opt. 2021, 60, 5465-5470. [CrossRef] [PubMed] 